\title{
Plasma IncRNA expression profile as a prognostic tool in BRAF- mutant metastatic melanoma patients treated with BRAF inhibitor
}

\author{
Tomasz Kolenda ${ }^{1,2}$, Piotr Rutkowski ${ }^{4}$, Michał Michalak5 ${ }^{5}$ Katarzyna Kozak ${ }^{4}$, Kacper \\ Guglas $^{1,2,3}$, Marcel Ryś ${ }^{1}$, kukasz Galus ${ }^{6,7}$, Sebastian Woźniak ${ }^{6}$, Iwona Kugowska ${ }^{4,8}$, \\ Aleksandra Gos $^{9}$, Anna Teresiak ${ }^{2}$, Andrzej Mackiewicz ${ }^{1,10}$, Katarzyna Lamperska ${ }^{2}$ \\ and Jacek Mackiewicz ${ }^{6,10,11}$ \\ ${ }^{1}$ Department of Cancer Immunology, Chair of Medical Biotechnology, Poznan University of Medical Sciences, Poznan, Poland \\ ${ }^{2}$ Laboratory of Cancer Genetics, Greater Poland Cancer Centre, Poznan, Poland \\ ${ }^{3}$ Postgraduate School of Molecular Medicine, Medical University of Warsaw, Warsaw, Poland \\ ${ }^{4}$ Department of Soft Tissue/Bone Sarcoma and Melanoma, Maria Sklodowska-Curie Institute - Oncology Center, Warsaw, \\ Poland \\ ${ }^{5}$ Department of Computer Science and Statistics, University of Medical Sciences, Poznan, Poland \\ ${ }^{6}$ Department of Medical and Experimental Oncology, Heliodor Swiecicki Clinical Hospital, Poznan University of Medical \\ Sciences, Poznan, Poland \\ ${ }^{7}$ Department of Chemotherapy, Greater Poland Cancer Centre, Poznan, Poland \\ ${ }^{8}$ Early Phase Clinical Trials Unit, Maria Sklodowska-Curie Institute - Oncology Center, Warsaw, Poland \\ ${ }^{9}$ Department of Translational Oncology, Maria Sklodowska-Curie Institute - Oncology Center, Warsaw, Poland \\ ${ }^{10}$ Department of Diagnostics and Cancer Immunology, Greater Poland Cancer Centre, Poznan, Poland \\ ${ }^{11}$ Department of Biology and Environmental Sciences, Poznan University of Medical Sciences, Poznan, Poland \\ Correspondence to: Tomasz Kolenda, email: kolenda.tomek@gmail.com \\ Jacek Mackiewicz, email: jmackiewicz@ump.edu.pl
}

Keywords: melanoma; BRAF mutation; BRAF inhibitor; IncRNA; liquid biopsy

Received: December 06, $2018 \quad$ Accepted: May 13, $2019 \quad$ Published: June 11, 2019

Copyright: Kolenda et al. This is an open-access article distributed under the terms of the Creative Commons Attribution License 3.0 (CC BY 3.0), which permits unrestricted use, distribution, and reproduction in any medium, provided the original author and source are credited.

\section{ABSTRACT}

Long non-coding RNAs (IncRNA) are dysregulated in many cancer types. Abnormal baseline levels of these IncRNAs display diagnostic and prognostic potential in cancer patients. The aim of this study was to evaluate the prognostic value of plasma IncRNAs in BRAF-mutant advanced melanoma patients treated with a BRAF inhibitor. Total RNA was isolated from plasma samples collected from $\mathbf{5 8}$ advanced BRAF-mutant melanoma patients and 15 healthy donors. The expression levels of 90 IncRNAs were estimated using the LncProfiler qPCR Array Kit (SBI) and LightCycler 96 (Roche). LncRNA expression levels correlated with responses to the BRAF inhibitor (vemurafenib) treatment. The patients were stratified into three groups based on their IncRNA levels with various IncRNA expressions (low, medium, and high). A Cox proportional hazards regression model was used to determine the IncRNAs that were significantly associated with both progression-free and overall survivals (PFS and $O S$, respectively) in patients receiving vemurafenib. The expression level of 12 IncRNAs was down-regulated, while five IncRNAs were up-regulated in melanoma patients compared to healthy donors. Kaplan-Meier analysis showed that upregulation or downregulation of 11 and 16 different IncRNAs were associated with longer median PFS and OS, respectively. Further analysis demonstrated that the baseline IncRNAs for IGF2AS, anti-Peg11, MEG3, Zeb2NAT are independent prognostic factors in BRAF- 


\section{mutant advanced melanoma patients treated with vemurafenib. Evaluation of plasma IncRNAs expression level for advanced melanoma diagnosis and prognosis evaluation appears to be a safe and valuable method; however, this method requires further validation in larger cohorts and randomized trials.}

\section{INTRODUCTION}

The treatment landscape in melanoma is rapidly changing. The introduction of immunotherapy and targeted therapy to standard treatment regimens has improved the prognosis of melanoma patients. However, despite the significant progress in melanoma treatment modalities, a number of patients still do not respond to the therapy or develop resistance to the medicinal products and die early. Vemurafenib, the v-Raf murine sarcoma viral oncogene homolog B (BRAF) inhibitor was the first new generation drug approved for skin melanoma treatment. In a randomized phase 3 trial, it extended median overall survival (OS) for patients by four months compared to chemotherapy in BRAF-mutated advanced melanoma patients [1]. Subsequent clinical studies showed that addition of a mitogen-activated protein kinase kinase (MEK) inhibitor to the BRAF inhibitor translates into further survival improvement [2-7]. Various mechanisms of primary and secondary resistance to BRAF and MEK inhibitors have been described [8]. Moreover, novel prognostic biomarkers have been identified in patients treated with targeted therapy (BRAF and MEK inhibitors) and immunotherapy (anti-programmed cell death protein [PD]1 and anti-cytotoxic T-lymphocyte-associated antigen [CTLA]4) [9-11]. Accordingly, continuous research, including predictive biomarker identification, is required to guide physicians' decision on whether targeted therapy or immunotherapy should be applied for the first-line treatment in BRAF mutant patients in order to improve their survival.

Liquid biopsies provide non-invasive and easy sources of circulating RNAs [12-14]. Different types of both shorter and IncRNAs are detectable in the whole blood, serum, and plasma [15]. The lncRNAs are molecules $>200$ nucleotides and are actively transcribed but do not encode proteins. LncRNA molecules possess many functional domains, such as RNA, DNA, or protein binding sites and may play crucial physiological roles in controlling transcription and post-transcriptional processes and protein translation and/or may influence epigenetic modifications. They participate in proliferation, apoptosis, stress responses, and regulation of cell metabolism or cell phenotype [16]. LncRNAs are candidates for a new class of biomarkers [16, 17]. However, little is known about the role of circulating lncRNAs.

Application of various types of RNA as biomarkers is not new, but there is still a lack of specified diagnostic panels. Assessment of lncRNA expression in various specimens, such as tissue, urine, peripheral blood, serum, saliva, and/or urine may be easily done using different diagnostics methods, but real-time quantitative reverse transcription polymerase chain reaction (qRT-PCR) is the most frequently used method [17].

Accordingly we have analyzed the expression of 90 lncRNAs that are potentially connected with cancer. LncRNAs were assessed in the plasma of pretreated BRAF-mutated unresectable stage III and IV cutaneous melanoma patients and healthy donors in order to assess their potential as biomarkers of BRAF inhibitor treatment efficacy. We show that melanoma patients presented different plasma lncRNA levels than healthy donors. Moreover, we found that expression levels of some lncRNAs were linked with better outcomes in patients treated with the BRAF inhibitor. Furthermore, the levels of selected lncRNAs appeared to be linked with primary progression to BRAF inhibitor in melanoma patients.

\section{RESULTS}

\section{Patients}

Between June 2013 and November 2014, 58 patients with $B R A F$-mutated metastatic melanoma began treatment with vemurafenib. All of them had at least one response assessment in addition to available pretreatment plasma collection for further lncRNA analyses. The characteristics of the examined melanoma patients treated with vemurafenib are shown in Table 1.

\section{Plasma IncRNA expression differ in metastatic melanoma patients and healthy individuals}

The expression levels of $90 \operatorname{lncRNAs}$ that were potentially connected with the cancer process was evaluated in 58 BRAF-mutant metastatic melanoma patients and 15 healthy donors (controls) without any histories of cancer or chronic diseases. The plasma from melanoma patients was collected prior to the start of vemurafenib treatment. The expressions of the following 12 IncRNAs were significantly down-regulated in melanoma patients compared to healthy volunteers: (1) brain cytoplasmic (BC)200 $(0.251 \pm 0.081$ versus 1.722 $\pm 0.792 ; p=0.004) ;(2) \mathrm{E} 2 \mathrm{~F} 2$ antisense $(1.681 \pm 0.543$ versus $2.223 \pm 0.864 ; p=0.049$ ); (3) H19 antisense $(0.956 \pm 0.165$ versus $3.374 \pm 1.047 ; p=0.001)$; (4) homeobox transcript (HOTAIR) $(8.537 \pm 1.026$ versus $1.334 \mathrm{e}+06 \pm 9.450 \mathrm{e}+05 ; p=0.039$ ); (5) homeobox (HOX)A6as $(0.173 \pm 0.027$ versus $12.02 \pm 4.522 ; p=$ $0.001)$; (6) imprinted in Prader-Willi Syndrome (IPW) $(0.058 \pm 0.012$ versus $0.125 \pm 0.05 ; p=0.026)$; (7) 
Table 1: Baseline characteristics of BRAF-mutated melanoma patients treated with vemurafenib

\begin{tabular}{lcc}
\hline Parameters & & $\begin{array}{c}\text { Cases } \\
\boldsymbol{n}(\mathbf{\%})\end{array}$ \\
\hline Sex & Women & $29(50 \%)$ \\
& Man & $29(50 \%)$ \\
Age & $<54$ & $26(45 \%)$ \\
mean) & $>54$ & $32(55 \%)$ \\
LDH level & Normal & $43(74 \%)$ \\
& $>$ ULN & $11(19 \%)$ \\
Brain metastases & ND & $4(7 \%)$ \\
& Yes & $36(62 \%)$ \\
Earlier treatment & No & $22(38 \%)$ \\
& Yes & $9(15.5 \%)$ \\
Response to vemurafenib treatment & No & $49(84.5 \%)$ \\
& CR & $3(5 \%)$ \\
& PR & $30(52 \%)$ \\
\hline
\end{tabular}

CR - Complete Response; PR - Partial Response; SD - Stable Disease; PD - Progressive Disease; ULN - upper laboratory norm; ND - not done.

neuroblastoma differentiation marker (NDM)29 (1.661 \pm 0.882 versus $4.667 \pm 1.780 ; p=0.002) ;(8)$ ncRNA repressor of the nuclear factor of activated T-cells $(\mathrm{NRON})(0.042 \pm 0.006$ versus $0.116 \pm 0.025 ; p=$ $0.001)$; (9) small nucleolar RNA host gene (SNHG)1 $(0.025 \pm 0.013$ versus $0.062 \pm 0.013 ; p=0.029)$; (10) SNHG3 $(0.234 \pm 0.034$ versus $0.900 \pm 0.391$; $p=0.029$ ); (11) Wilms tumor-antisense (WT1-AS) $(0.036 \pm 0.027$ versus $0.148 \pm 0.066 ; p=0.005)$; and (12) zinc finger homeobox antisense (ZFHX2AS) (16.51 \pm 2.204 versus $179.9 \pm 63.48 ; p=0.002)$ as shown in Figure 1.

Expression levels of five lncRNAs were significantly up-regulated in melanoma patients compared to healthy volunteers. Increases in the expressions of several IncRNAs were observed, including chromatin-associated RNA (CAR)-intergenic-10 $(0.125 \pm 0.091$ versus 0.103 $\pm 0.02 ; p=0.001$ ), insulin-like growth factor 2-antisense (IGF2as) family $(0.935 \pm 0.335$ versus $0.373 \pm 0.351$; $p=0.025)$, potassium voltage-gated channel subfamily q overlapping transcript (KCNQ1OT1) $(1.755 \mathrm{e}+010 \pm$ $8.881 \mathrm{e}+009$ versus $0.062 \pm 0.023 ; p=0.028)$, antisense to $\mathrm{X}$-inactive specific transcript (Tsix) (35.24 \pm 9.326 versus $4.795 \pm 0.873 ; p=0.022)$, and potassium voltage-gated channel subfamily q (UM9-5) $(0.139 \pm 0.056$ versus 0.137 $\pm 0.035 ; p=0.002)$ as shown in Figure 2 .

The ROC analysis indicated lncRNA with high sensitivity (from $51.79 \%$ to $100 \%$ ) and specificity (from $50 \%$ to $100 \%$ ) could distinguish cancer from healthy patients. The results of the area under the ROC curve (AUC) analysis were summarized in Table 2.

\section{Correlation of plasma IncRNA expression with response to vemurafenib treatment in BRAF- mutant metastatic melanoma patients}

Associations between the expression level of lncRNAs and patients' response to vemurafenib treatment were analyzed. Patients were grouped according to treatment response (Table 1). The lncRNA expression levels in patients developing progressive disease (PD) were compared to those with objective response rates (complete and partial response [CR+PR] groups). Significant differences between the PD and $\mathrm{CR}+\mathrm{PR}$ groups were observed for antisense of IGF2R non-protein coding RNA (AIR) $(0.012 \pm 0.005$ versus $0.025 \pm 0.018$; $p=0.038$ ), antisense to zinc finger NFX1 (Zfas1) $(0.164$ \pm 0.038 versus $0.649 \pm 0.24 ; p=0.022)$, $7 \mathrm{SL}(1.522 \pm$ 0.363 versus $0.673 \pm 0.157 ; p=0.030$ ), and zinc finger AE-binding homeobox 2-natural antisense transcript (Zeb2NAT) $(0.109 \pm 0.03$ versus $0.068 \pm 0.022 ; p=0.045)$ as shown in Figure 3.

In the subgroups (PD versus $\mathrm{CR}+\mathrm{PR}$ ) presenting significant differences in lncRNA expression level the discrimination ratio was assessed using the ROC analysis, which showed AIR (AUC $=0.842 ; \mathrm{p}<0.0001)$, Zfas 1 $(\mathrm{AUC}=0.766 ; p=0.001), 7 \mathrm{SL}(\mathrm{AUC}=0.787 ; p=0.006)$, 
and Zeb2NAT $(\mathrm{AUC}=0.747 ; p=0.008)$ can differentiate between $\mathrm{CR}+\mathrm{PR}$ and $\mathrm{PD}$ groups.

\section{Plasma IncRNA expression level as biomarker} of progression-free survival and overall survival in BRAF-mutated metastatic melanoma patients treated with vemurafenib

Each of the 58 patients included in the analysis was classified into one of three sub-groups depending on the relative plasma lncRNA level (low, medium, or high). The groups were stratified by dividing the observed samples into tertiles as shown in Table 3. The median follow-up duration was 11 months. The median
PFS and OS in all studied patients were eight and 11 months, respectively. The expression levels of lncRNA in particular groups (Tertile I-III) was correlated with PFS and OS. In patients with high expression (Tertile III) of antiPEG11 $(p=0.018)$, HOTAIR $(p=0.034)$, IGF2AS $(p$ $=0.015)$, maternally expressed gene $(\mathrm{MEG}) 3(p=0.0004)$, prostate-specific transcript (PCGEM1 $(p=0.027)$, and polypyrimidine tract-binding protein-associated splicing factor (PSF) inhibiting RNA $(p=0.039)$, significantly longer PFS was observed compared to patients with low expression (Tertile I) of the corresponding lncRNAs. In patients with medium (Tertile II) level of lncRNAs, $21 \mathrm{~A}(p$ $=0.021)$, lincRNA-RoR $(p=0.032)$, Y-RNA $(p=0.005)$, and Zfas1 $(p=0.028)$, a significantly longer patient PFS
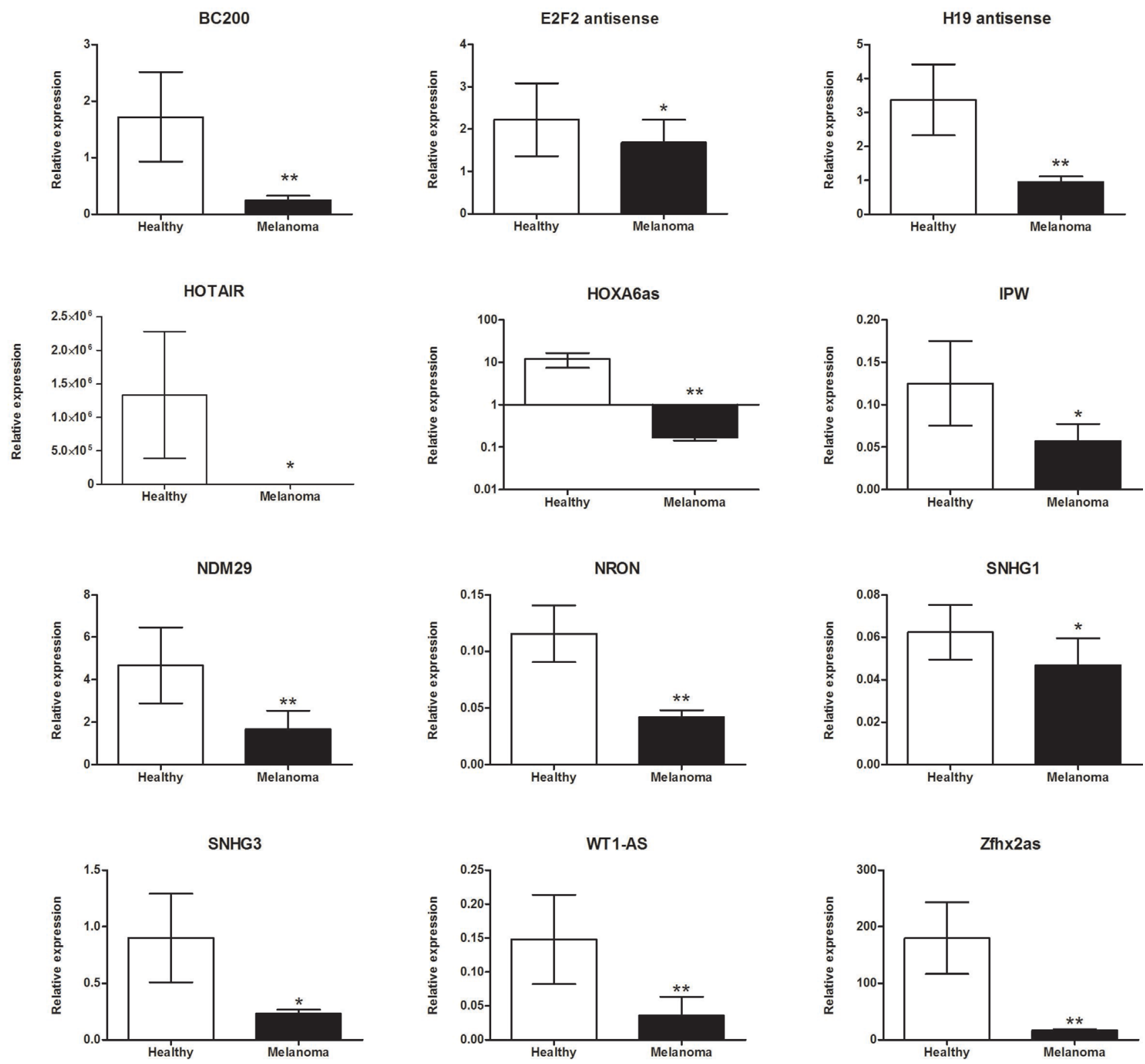

Figure 1: IncRNAs were significantly down-regulated in $B R A F$-mutant metastatic melanoma patients compared to healthy donors. Data present mean expression with standard error (SEM); ${ }^{*} p<0.05,{ }^{* *} p<0.01$. 
was observed compared to patients with high expression (Tertile III) of the corresponding lncRNAs. Patients with low (Tertile I) levels of Zeb2NAT showed longer PFS compared to patients with high (Tertile III) Zeb2NAT levels ( $p=0.0004$, Figure 4).

The OS of patients with high levels (Tertile III) of antiPEG11 $(p=0.026)$, HOTAIR $(p=0.013)$, IGF2AS $(p$ $=0.019)$, maternally expressed gene $(\mathrm{MEG}) 3(p=0.0000)$, neuroendocrine secretory protein antisense (Nespas) $(p=0.042)$, PCGEM1 $(p=0.008)$, PSF inhibiting RNA $(p=0.035)$ and sex determining region-overlapping transcript (SOX2ot) $(p=0.035)$ was significantly longer than in patients with low (Tertile I) level of corresponding lncRNAs. With respect to lncRNAs, 21A ( $p=0.011)$, HAR1A $(p=0.044)$, ncR-uPAR $(p=0.047)$, Y-RNA $(p=0.033)$, and Zfas1 $(p=0.015)$, a significantly longer OS was observed in patients with medium compared to high levels of corresponding lncRNAs (Tertile II versus III). In patients with low (Tertile I) small nucleolar RNA host gene (SNHG1) $(p=0.019)$ and Zeb2NAT $(p=0.011)$ expressions, longer OS was seen compared to patients with high levels (Tertile III) of corresponding lncRNAs (Figure 5).

We next evaluated the prognostic value of the differentially expressed lncRNAs using univariate and multivariate Cox regression analyses. The univariate analysis showed that lactate dehydrogenase (LDH) serum levels, brain metastases, earlier systemic treatment, and lncRNA serum levels of antiPeg11, IGF2AS, MEG3, SOX2ot, and Zeb2NAT were significantly associated with patient PFS and OS as shown in Table 4. The abovementioned parameters were further analyzed using a multivariate analysis, and antiPeg11, IGF2AS, MEG3,
SOX2ot, and Zeb2NAT were identified as statistically significant prognostic factors (Table 5).

Table 6 lists the correlation between antiPeg11, IGF2AS, MEG3, SOX2ot, and Zeb2NAT expression levels in serum and the clinical characteristics of $B R A F$-mutated advanced melanoma patients treated with vemurafenib. A higher level of plasma Zeb2NAT correlated with the occurrence of brain metastases $(p=0.032)$. Moreover, a higher level of plasma SOX2ot correlated with male gender $(p=0.030)$. However, we did not observe any association between the expressions of the remaining lncRNA and patients ages, sexes, LDH levels, occurrence of brain metastases, and/or earlier applied systemic treatment.

\section{DISCUSSION}

This study included three main findings: (1) plasma lncRNA levels differed in BRAF-mutated advanced melanoma patients and healthy controls; (2) expression levels of selected lncRNA were linked with favorable median PFS and OS of patients treated with BRAF inhibitor; and (3) plasma levels of particular lncRNAs were linked with primary progression of the disease in patients treated with BRAF inhibitor.

Although some driver mutations in $B R A F$ or $N R A S$ genes have been identified in melanoma, the efficiencies of their inhibitors are still limited [18-22]. The BRAF mutations occur in about $50 \%$ of patients with skin melanoma. These patients can be treated with BRAF inhibitors (vemurafenib or dabrafenib) alone or in combination with MEK inhibitors (cobimetinib or trametinib), which is the currently recommended treatment plan. The objective response rate (CR and PR) is observed in $50 \%$ to $70 \%$ of patients; however, about half of them
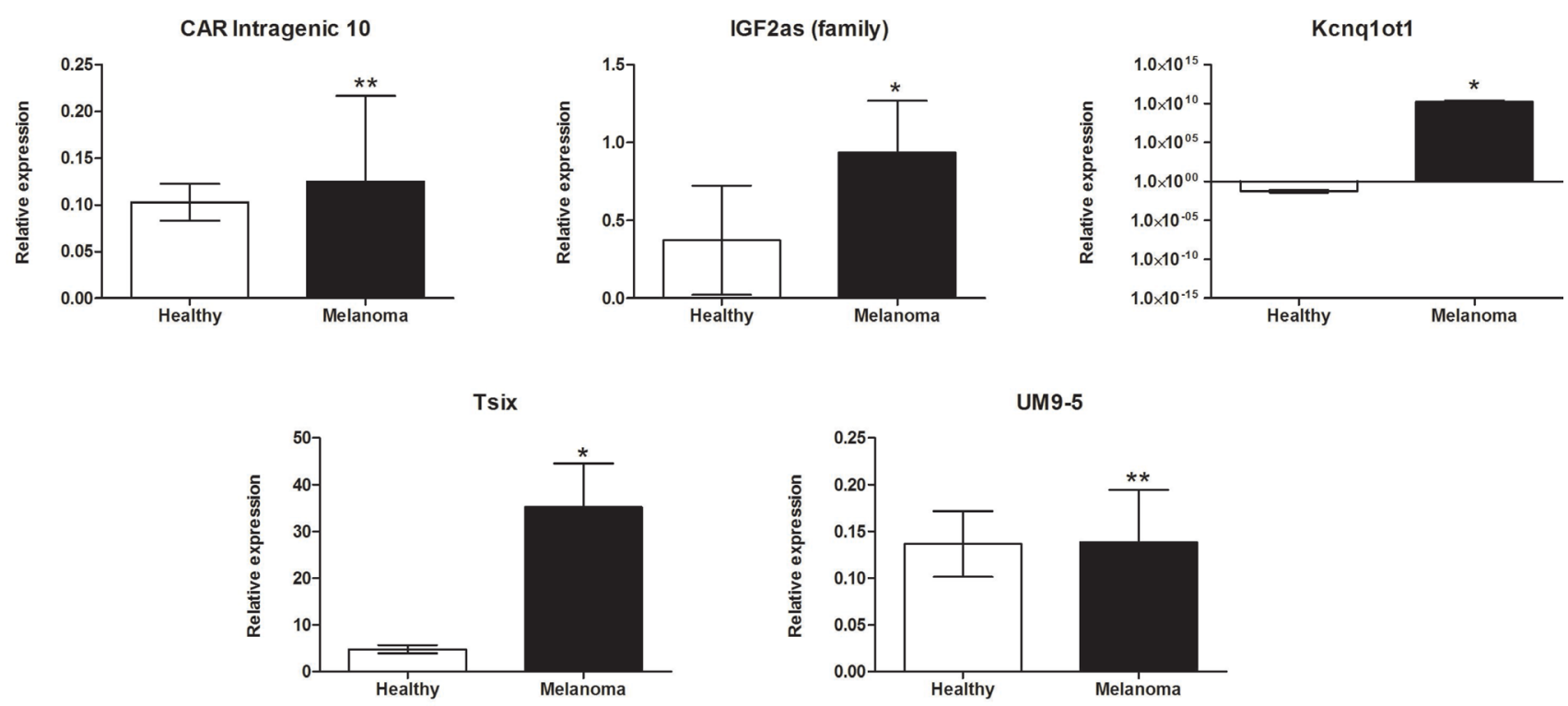

Figure 2: IncRNAs significantly up-regulated in $B R A F$-mutant metastatic melanoma patients compared to healthy donors. Data present mean expression with standard error (SEM); ${ }^{*} p<0.05,{ }^{* *} p<0.01$. 
Table 2: IncRNA sensitivity and specificity features for distinguishing cancer and healthy patients; receiver operating characteristic (ROC) curve analysis

\begin{tabular}{lcccc}
\hline IncRNA & AUC & Sensitivity & Specificity & $\boldsymbol{P}$-value \\
\hline CAR Intragenic 10 & 0.807 & 68.09 & 90.91 & $<\mathbf{0 . 0 0 0 1}$ \\
NDM29 & 0.792 & 61.54 & 90.91 & $<\mathbf{0 . 0 0 0 1}$ \\
H19 antisense & 0.791 & 51.79 & 100.00 & $<\mathbf{0 . 0 0 0 1}$ \\
HOXA6as & 0.787 & 100.00 & 61.54 & $\mathbf{0 . 0 0 1 2}$ \\
NRON & 0.780 & 76.79 & 76.92 & $\mathbf{0 . 0 0 0 1}$ \\
Zfhx2as & 0.769 & 100.00 & 50.00 & $\mathbf{0 . 0 0 0 4}$ \\
IPW & 0.767 & 53.66 & 100.00 & $\mathbf{0 . 0 0 0 8}$ \\
BC200 & 64.15 & 84.62 & $\mathbf{0 . 0 0 0 2}$ \\
UM9-5 & 0.763 & 72.73 & 80.00 & $<\mathbf{0 . 0 0 0 1}$ \\
WT1-AS & 0.759 & 95.45 & 61.54 & $\mathbf{0 . 0 0 3 8}$ \\
Kcnq1ot1 & 72.73 & 77.78 & $\mathbf{0 . 0 0 2 7}$ \\
Tsix & 0.753 & 56.25 & 100.00 & $\mathbf{0 . 0 0 0 3}$ \\
IGF2as (family) & 0.735 & 51.79 & 91.67 & $\mathbf{0 . 0 1 4 1}$ \\
SNHG3 & 0.731 & 83.64 & 50.00 & $\mathbf{0 . 0 2 1 9}$ \\
SNHG1 & 0.707 & 76.79 & 61.54 & $\mathbf{0 . 0 1 6 4}$ \\
E2F2 antisense & 0.703 & 65.31 & 72.73 & $\mathbf{0 . 0 1 8 6}$ \\
HOTAIR & 0.696 & 58.14 & 80.00 & $\mathbf{0 . 0 2 2 1}$ \\
\hline
\end{tabular}

will develop resistance to the treatment after 6 to 11 months of therapy $[3,5,21,23]$.

Cancer diagnosis and prognosis employing circulating lncRNAs are preferable when compared to classical biopsies of tumor tissues, especially due to their noninvasiveness and their increasing potential for routine use in clinical practice. LncRNAs can be actively released by tumor tissues and cells [27]. However, elevated quantities of lncRNAs in plasma may originate from multiple sources, including cancer-adjacent normal
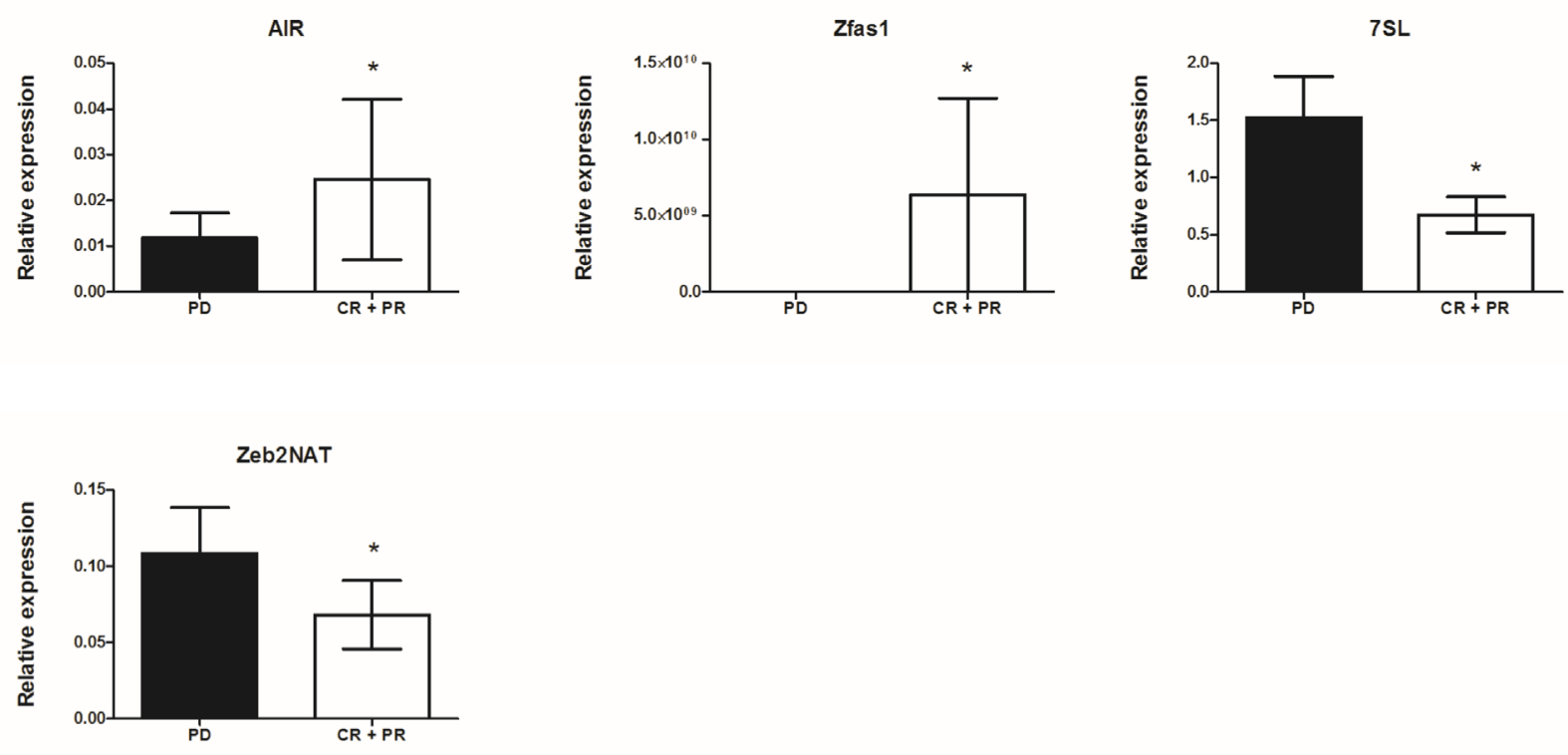

Figure 3: Correlation of IncRNA expression with response to vemurafenib treatment in metastatic melanoma patients; mean expression with standard error (SEM); ${ }^{*} p<0.05,{ }^{* *} p<0.01$. 
Table 3: The plasma IncRNA levels in melanoma patients displaying low, medium, and high expressions

\begin{tabular}{llll}
\hline IncRNA & Low (tertile I) & Medium (tertile II) & High (tertile III) \\
\hline antiPEG11 & $1.11 \mathrm{E}-16-1.43 \mathrm{E}-04$ & $1.43 \mathrm{E}-04-2.51 \mathrm{E}-03$ & $2.51 \mathrm{E}-03-2.35 \mathrm{E}+11$ \\
HOTAIR & $1.50 \mathrm{E}-11-5.25 \mathrm{E}+00$ & $5.25 \mathrm{E}+00-8.66 \mathrm{E}+00$ & $8.66 \mathrm{E}+00-3.38 \mathrm{E}+01$ \\
IGF2AS & $9.39 \mathrm{E}-16-2.27 \mathrm{E}-02$ & $2.27 \mathrm{E}-02-3.46 \mathrm{E}-01$ & $3.46 \mathrm{E}-01-1.53 \mathrm{E}+01$ \\
Meg3 & $2.78 \mathrm{E}-17-1.32 \mathrm{E}-03$ & $1.32 \mathrm{E}-03-1.08 \mathrm{E}-02$ & $1.08 \mathrm{E}-02-2.08 \mathrm{E}+11$ \\
PCGEM1 & $2.62 \mathrm{E}-06-2.74 \mathrm{E}-03$ & $2.74 \mathrm{E}-03-3.63 \mathrm{E}-02$ & $3.63 \mathrm{E}-02-2.35 \mathrm{E}+11$ \\
PSF inhibiting RNA & $2.78 \mathrm{E}-14-2.21 \mathrm{E}-01$ & $2.21 \mathrm{E}-01-1.58 \mathrm{E}+11$ & $1.58 \mathrm{E}+11-2.39 \mathrm{E}+11$ \\
21A & $2.74 \mathrm{E}-12-7.38 \mathrm{E}-01$ & $7.38 \mathrm{E}-01-2.92 \mathrm{E}+00$ & $2.92 \mathrm{E}+00-1.06 \mathrm{E}+02$ \\
lincRNA-RoR & $1.20 \mathrm{E}-15-3.23 \mathrm{E}+00$ & $3.23 \mathrm{E}+00-3.30 \mathrm{E}+02$ & $3.30 \mathrm{E}+02-2.08 \mathrm{E}+11$ \\
Y-RNA & $1.70 \mathrm{E}-08-1.34 \mathrm{E}+02$ & $1.34 \mathrm{E}+02-3.83 \mathrm{E}+02$ & $3.83 \mathrm{E}+02-2.23 \mathrm{E}+03$ \\
Zfas1 & $1.16 \mathrm{E}-13-1.56 \mathrm{E}-01$ & $1.56 \mathrm{E}-01-3.93 \mathrm{E}-01$ & $3.93 \mathrm{E}-01-2.04 \mathrm{E}+11$ \\
Zeb2NAT & $3.15 \mathrm{E}-13-2.56 \mathrm{E}-02$ & $2.56 \mathrm{E}-02-8.19 \mathrm{E}-02$ & $8.19 \mathrm{E}-02-2.08 \mathrm{E}+11$ \\
Nespas & $2.39 \mathrm{E}-13-6.67 \mathrm{E}-02$ & $6.67 \mathrm{E}-02-1.39 \mathrm{E}-01$ & $1.39 \mathrm{E}-01-2.04 \mathrm{E}+11$ \\
Sox2ot & $4.18 \mathrm{E}-13-6.29 \mathrm{E}-03$ & $6.29 \mathrm{E}-03-3.88 \mathrm{E}-02$ & $3.88 \mathrm{E}-02-2.35 \mathrm{E}+11$ \\
HAR1A & $2.98 \mathrm{E}-14-8.23 \mathrm{E}-03$ & $8.23 \mathrm{E}-03-3.81 \mathrm{E}-02$ & $3.81 \mathrm{E}-02-1.91 \mathrm{E}-01$ \\
ncR-uPAR & $6.70 \mathrm{E}-13-3.73 \mathrm{E}-02$ & $3.73 \mathrm{E}-02-2.09 \mathrm{E}-01$ & $2.09 \mathrm{E}-01-5.07 \mathrm{E}+00$ \\
SNHG1 & $2.74 \mathrm{E}-13-8.19 \mathrm{E}-03$ & $8.19 \mathrm{E}-03-3.97 \mathrm{E}-02$ & $3.97 \mathrm{E}-02-6.66 \mathrm{E}-01$ \\
\hline
\end{tabular}

cells, immune cells, and other blood cells [28, 29]. In our study we identified 12 downregulated and five upregulated plasma lncRNAs in BRAF-mutated metastatic melanoma compared to healthy individuals. The ROC analysis indicated lncRNA with high sensitivity and specificity for distinguishing between cancer and healthy patients. To our knowledge, this is the largest study showing the difference in the expression profile of circulating lncRNAs in $B R A F$-mutated melanoma patients and healthy donors. These data show that dysregulated plasma lncRNAs can help make diagnoses of $B R A F$-mutated advanced melanoma with high sensitivity and specificity. However, evaluation of the above specified dysregulated plasma lncRNAs in the primary diagnosis of melanoma needs further investigation. In addition, circulating IGF2as was identified as an independent factor for $B R A F$-mutated advanced melanoma prognosis in patients receiving vemurafenib.

Elevated serum LDH, presence of brain metastases, and earlier systemic treatment are well known negative prognostic markers in melanoma regardless of the applied treatment [11, 21, 22]. In our study, these factors were linked with poor OS in the univariate analysis. However, they lost their significance in the multivariate analysis probably due to the small sample size. The Kaplan-Meier curves showed that higher plasma levels of antiPeg11 (PFS: 9 versus six months; OS: 12 versus 9 months), IGF2AS (PFS: 12 versus six months; OS: 21 versus nine months), and MEG3 (PFS: 9 versus 6 months; OS: 13 versus 6 months) were linked with longer median PFSs and OSs compared to lower levels. The higher SOX2ot plasma level was linked to longer median OS (12 versus
6 months) but not median PFS. Moreover, low levels of Zeb2NAT were linked with longer median PFS (13 versus 6 months) and median OS (15 versus 8 months) compared to higher levels. Furthermore, univariate and multivariate Cox regression models showed that elevated baseline plasma levels of antiPeg11, MEG3, and SOX2ot and decreased level of Zeb2NAT appear to be positive prognostic factors linked with longer PFS and OS. However, higher levels of plasma SOX2ot might be also linked with female gender. The univariate analysis also showed that higher expression level of IGF2as was linked with longer PFS and OS, however the multivariate analysis showed significant difference only in OS. When taken together, these results demonstrate that lncRNA IGF2AS, antiPeg11, MEG3, and Zeb2NAT appear to be independent prognostic factors in $B R A F$-mutated advanced melanoma patients treated with vemurafenib.

The function of theses circulating lncRNAs is still unknown. Moreover, they probably are derived from tumor cells; however, their origin from inflammatory cells is also possible. Zeb2NAT lncRNA is a regulator of Zeb2, one of the major transcription factors involved in epithelial-mesenchymal transition (EMT) and was shown to directly represses E-cadherin during epithelial-mesenchymal transition (EMT) [24]. There are two mechanisms involved in the regulation of Zeb2 expression: (1) at the transcriptional level and (2) at the posttranscriptional level by lncRNA Zeb2NAT. It was shown that cancer-associated fibroblasts secrete transforming growth factor (TGF)-beta1 that up-regulated Zeb2NAT, leading to Zeb2 activation and EMT induction that was responsible for bladder cancer cell invasion 
[24]. It was also shown that Zeb2 is involved in acquired resistance to the BRAF inhibitor in $B R A F$-mutated melanoma. Mechanistically, it was shown that the BRAF inhibitor induces activation of Zeb2, which stimulates Mer tyrosine kinase (MerTK) through target of rapamycin complex (TORC)1-triggered activation of autophagy leading to secondary resistance to BRAF inhibition and melanoma cell growth [25]. It was previously shown that IGF2 promotes cancer development and progression [26]. Upregulation of IGF2anti-sense inhibits IGF2 in murine neurons $[27,28]$ and human non-small cell lung cancer (NCSLC) cell lines [29]. In NCSLC, upregulation of IGF2as inhibited vascular endothelial growth factor (VEGF) and basic fibroblast growth factor (bFGF) expressions probably through IGF2 inhibition [29]. It was shown that in NSCLC patient tissues, downregulated
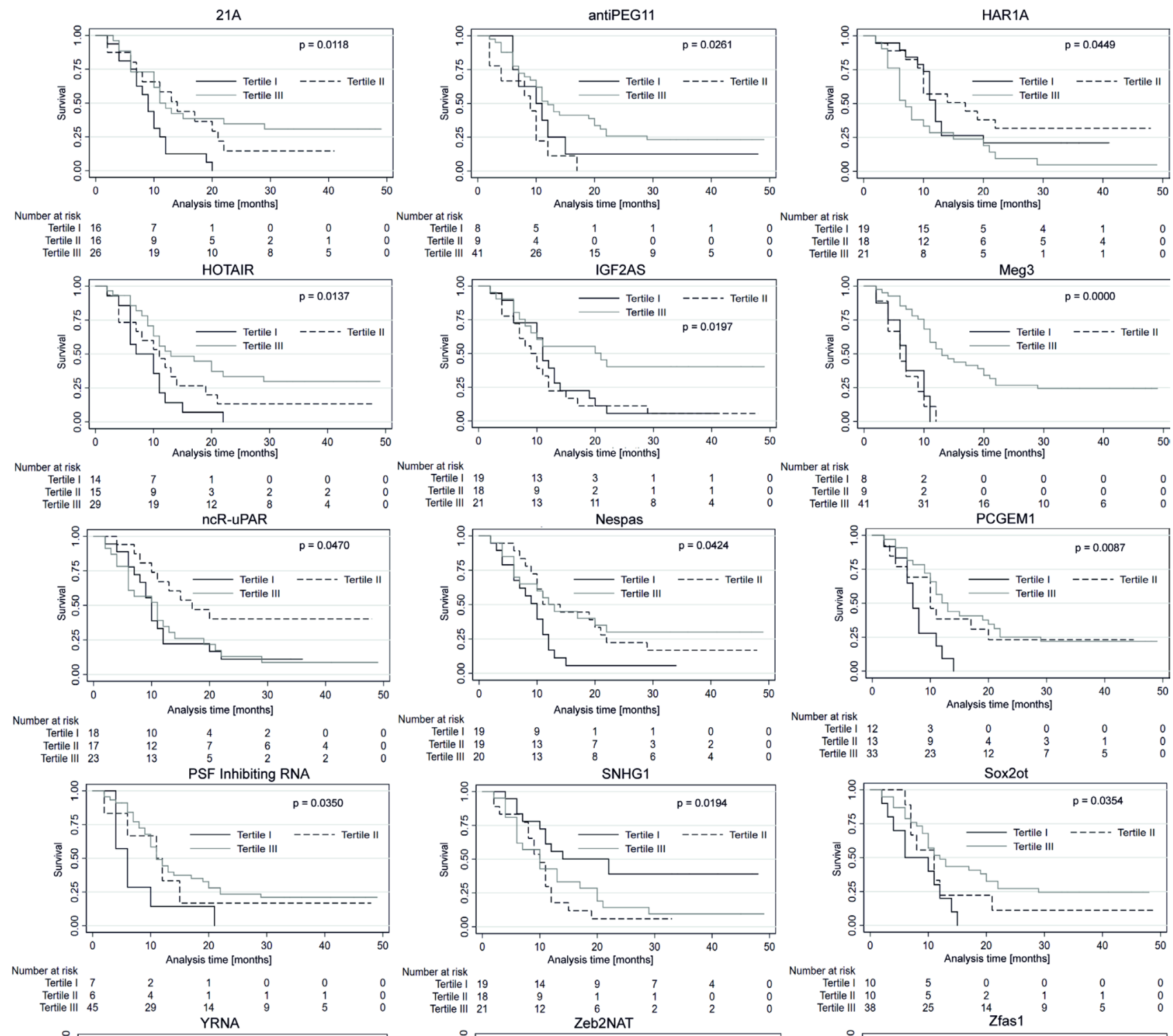

$\begin{array}{cr} & \text { Number at risk } \\ 0 & \text { Tertile I } \\ 0 & \text { Tertile II } \\ 0 & \text { Tertile III }\end{array}$
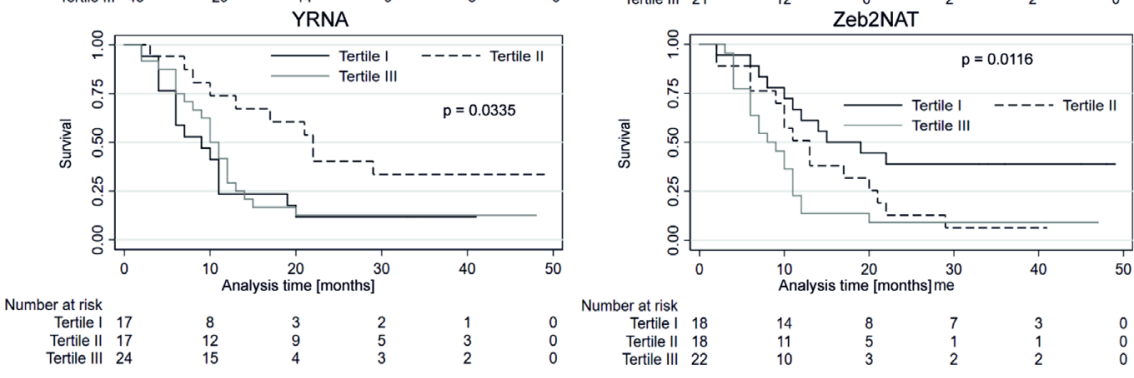

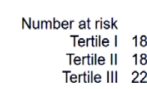

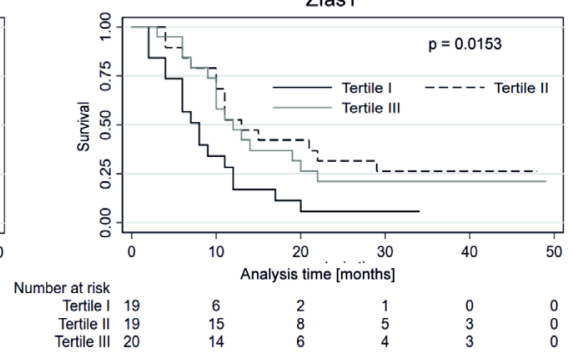

Figure 4: Progression-free survival probability curves of the three subgroups stratified based on low, medium and high expression of IncRNAs. Kaplan-Meier survival estimates test; $p<0.05$ considered as significant. 
IGF2as expression was linked with much worse OS than in NSCLC patients with upregulated IGF2as expression [29]. In our study, IGF2as was upregulated in BRAFmutated advanced melanoma patients compared to healthy donors, and its high expression level was linked to more favorable survival. However, the function of circulating IGF2as in cancer is still unknown. Upregulation of MEG3 inhibited melanoma cell proliferation, invasion, and migration, enhanced melanoma cell apoptosis, and arrested melanoma cell cycle. Overexpression of MEG3 suppressed the growth of xenograft tumors and improved chemotherapy sensitivity of A375 cells to cisplatin and 5-FU treatment [30]. However, there is a lack of data concerning circulating MEG3 in cancer. In our study, high levels of plasma MEG3 were linked with longer survival compared to low levels of this lncRNA. The role and source of circulating MEG3 in cancer patients is unknown. To our knowledge, this is the first report on circulating
MEG3 in cancer patients. Another dysregulated lncRNA in our analysis was antiPeg11. To our knowledge, antiPeg11 has not yet been described, so its function in cancer is unknown. SOX2ot is upregulated and appears to function a an oncogene in multiple types of cancers; however, some studies show that SOX2ot may play a tumor suppressor role [31-37]. It was shown that low serum expressions of SOX2ot were associated with longer OS. However, this study was performed in NCSLC patients in the Chinese population [38]. To our knowledge, SOX2ot has not been previously described in melanoma patients. These reports further strengthen our finding that circulating lncRNA IGF2AS, antiPeg11, MEG3, and Zeb2NAT have immense potential to serve as biomarkers in patients treated with BRAF inhibitors.

Primary progression at first tumor assessment, performed after two months of vemurafenib therapy, was linked with pretreatment plasma upregulation of

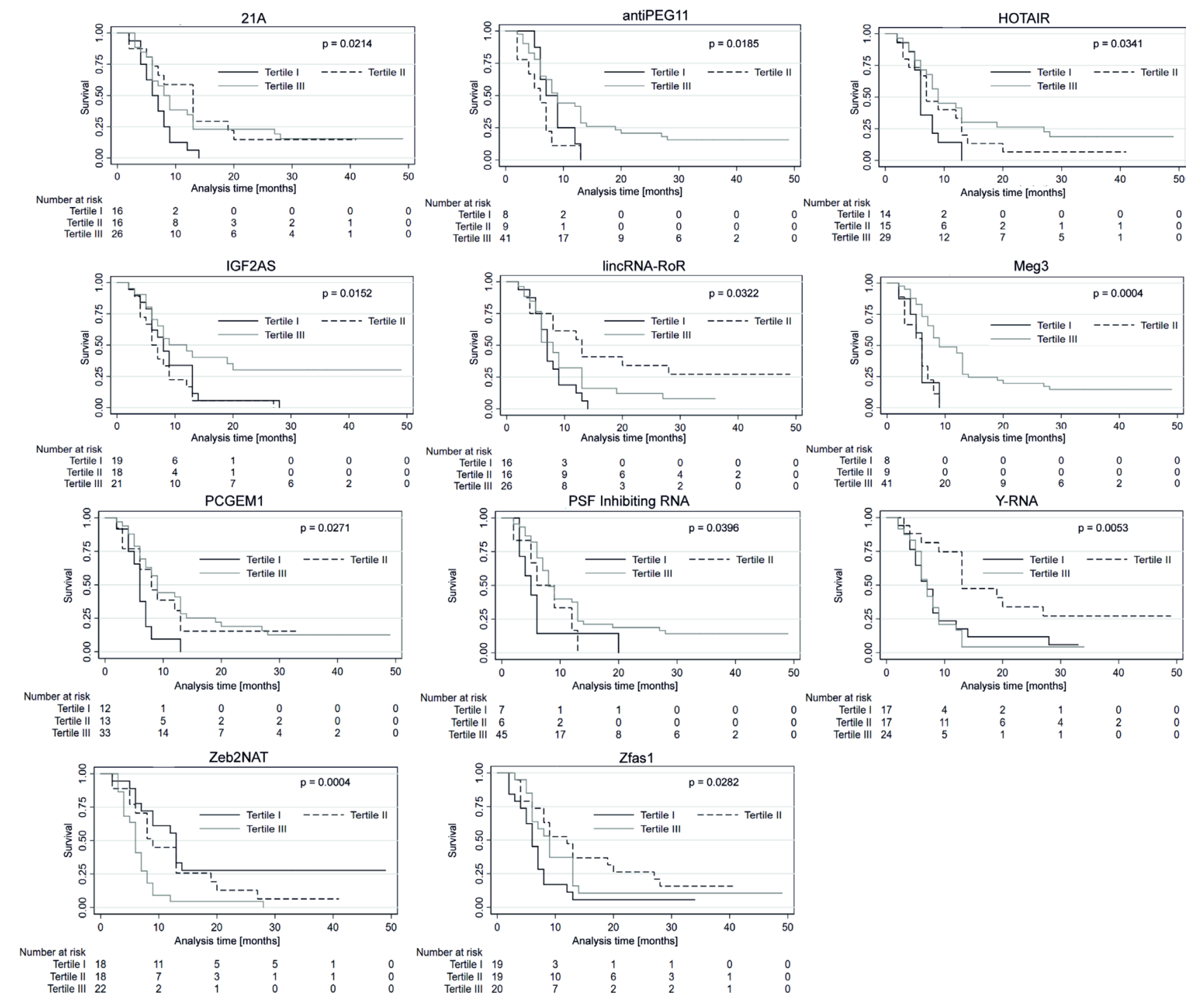

Figure 5: Overall survival (OS) probability curves of the three subgroups stratified based on low, medium and high expression of IncRNAs. Kaplan-Meier survival estimates test; $p<0.05$ considered as significant. 
Table 4: Univariate Cox regression analysis in $B R A F$-mutant melanoma patients treated with vemurafenib

\begin{tabular}{|c|c|c|c|c|c|c|c|}
\hline \multirow{2}{*}{ Parameters } & \multirow{2}{*}{ Categories } & \multicolumn{3}{|c|}{ Progression-free survival } & \multicolumn{3}{|c|}{ Overall survival } \\
\hline & & $P$-value & HR & $95 \% \mathrm{CI}$ & $P$-value & HR & $95 \% \mathrm{CI}$ \\
\hline Age & $>54$ vs $<54$ & 0.0582 & 1.03 & $1.00-1.07$ & 0.0526 & 1.04 & $1.00-1.07$ \\
\hline LDH & $>\mathrm{ULN}$ vs normal & 0.0431 & 3.11 & $1.12-5.93$ & 0.0100 & 3.23 & $1.32-7.89$ \\
\hline Brain metastases & yes vs no & 0.0273 & 2.48 & $1.11-5.55$ & 0.0031 & 3.81 & $1.57-9.22$ \\
\hline Earlier treatment & yes vs no & 0.0387 & 3.23 & $1.06-9.85$ & 0.0144 & 3.89 & $1.31-11.56$ \\
\hline Gender & male vs female & 0.7799 & 1.11 & $0.54-2.27$ & 0.4494 & 1.33 & $0.63-2.81$ \\
\hline antiPeg11 expression & high vs low & 0.0486 & 3.11 & $1.65-8.86$ & 0.0460 & 3.31 & $1.64-9.16$ \\
\hline antiPeg11 expression & high vs medium & 0.0414 & 3.22 & $1.75-8.69$ & 0.0481 & 3.83 & $1.65-10.14$ \\
\hline HOTAIR expression & high vs low & 0.3843 & 0.54 & $0.13-2.17$ & 0.9114 & 1.07 & $0.32-3.62$ \\
\hline HOTAIR expression & high vs medium & 0.7965 & 0.88 & $0.34-2.28$ & 0.8072 & 0.88 & $0.32-2.41$ \\
\hline IGF2AS expression & high vs low & 0.0460 & 3.37 & $1.93-8.90$ & 0.0490 & 3.52 & $1.90-11.06$ \\
\hline IGF2AS expression & high vs medium & 0.0301 & 4.04 & $1.89-6.31$ & 0.0324 & 4.66 & $1.91-12.75$ \\
\hline MEG3 expression & high vs low & 0.0499 & 3.10 & $2.01-7.09$ & 0.0393 & 3.02 & $1.63-10.73$ \\
\hline MEG3 expression & high vs medium & 0.0426 & 3.41 & $1.04-11.19$ & 0.0107 & 2.52 & $1.45-17.34$ \\
\hline Nespas expression & high vs low & 0.7308 & 0.83 & $0.29-2.41$ & 0.4067 & 1.55 & $0.55-4.39$ \\
\hline Nespas expression & high vs medium & 0.6017 & 0.80 & $0.35-1.85$ & 0.7108 & 0.85 & $0.36-1.99$ \\
\hline PCGEM1 expression & high vs low & 0.6222 & 1.36 & $0.40-4.56$ & 0.3339 & 1.85 & $0.53-6.4$ \\
\hline PCGEM1 expression & high vs medium & 0.6999 & 0.82 & $0.29-2.30$ & 0.3569 & 1.59 & $0.59-4.26$ \\
\hline PSFinhibitingRNA expression & high vs low & 0.3375 & 1.83 & $0.53-6.29$ & 0.2861 & 1.92 & $0.58-6.38$ \\
\hline PSFinhibitingRNA expression & high vs medium & 0.7645 & 0.77 & $0.14-4.29$ & 0.0578 & 0.20 & $0.04-1.05$ \\
\hline Sox 2ot expression & high vs low & 0.0450 & 3.86 & $1.64-10.75$ & 0.0190 & 4.15 & $1.93-12.78$ \\
\hline Sox $20 t$ expression & high vs medium & 0.4880 & 3.17 & $0.91-9.74$ & 0.0147 & 3.05 & $1.95-11.05$ \\
\hline SNHG1 expression & high vs low & 0.1722 & 0.48 & $0.17-1.38$ & 0.0314 & 0.42 & $0.19-0.92$ \\
\hline SNHG1 expression & high vs medium & 0.8663 & 1.09 & $0.40-2.96$ & 0.3473 & 1.42 & $0.68-2.95$ \\
\hline Zeb2NAT expression & high vs low & 0.0039 & 0.24 & $0.09-0.63$ & 0.0015 & 0.29 & $0.13-0.62$ \\
\hline Zeb2NAT expression & high vs medium & 0.0268 & 0.33 & $0.12-0.88$ & 0.0491 & 0.34 & $0.26-0.72$ \\
\hline
\end{tabular}

HR - hazard ratio; CI - confidence interval; LDH - lactate dehydrogenase; ULN - upper laboratory norm

7SL and Zeb2NAT and downregulation of Zfas1 and AIR. Inversely, downregulation of 7SL and Zeb2NAT, and upregulation of Zfas1 and AIR was linked with objective responses $(\mathrm{CR}+\mathrm{PR})$ to therapy. Most of the patients responded to vemurafenib treatment. In our study, CR and PR were noted in $56 \%$ of patients, while stable disease was observed in $29 \%$ and primary progression in $14 \%$ of patients. Zfas 1 is an lncRNA that has recently been reported to function as a potential oncogene by promoting cell proliferation and metastasis in several human cancers [39-42]. High Zfas 1 expression has been proven as an unfavorable prognostic biomarker for many types of cancers; however, in melanoma it has not yet been described [41, 43-48]. Furthermore, in breast cancer Zfas 1 inhibited cell proliferation, migration, invasion, and the EMT process. It was shown that Zfas1 overexpression inhibited cell proliferation by arresting the cell cycle at the G0/G1 phase and promoting cell apoptosis. In breast cancer cells overexpressing Zfas1, the EMT-related markers, such as E-cadherin expression, were upregulated while $\mathrm{N}$-cadherin and vimentin expressions were downregulated, indicating that the effects of Zfas1on cell migration and invasion were partially associated with the EMT process [49]. Another upregulated lncRNA-linked primary progression was $7 \mathrm{SL}$. This 1 ncRNA was found to be over-expressed in many tumors [50] and promoted growth of cancer cells by repressing P53 translation [51]. However, to our knowledge it has not been described in melanoma. Also the downregulated AIR was not yet characterized. These four lncRNAs (Zeb2NAT, Zfas1, 7SL, and AIR) might be involved in mechanisms of resistance to vemurafenib and serve as biomarkers of 
Table 5: Multivariate Cox regression analysis in $B R A F$-mutant melanoma patients treated with vemurafenib

\begin{tabular}{|c|c|c|c|c|c|c|c|}
\hline Parameters & Categories & $P$-value & HR & $95 \% \mathrm{CI}$ & $P$-value & HR & $95 \% \mathrm{CI}$ \\
\hline $\begin{array}{l}\text { antiPeg11 } \\
\text { expression }\end{array}$ & high vs low & 0.5702 & 1.43 & $0.41-4.98$ & 0.4458 & 0.54 & $0.11-2.62$ \\
\hline $\begin{array}{l}\text { antiPeg11 } \\
\text { expression }\end{array}$ & $\begin{array}{l}\text { high vs } \\
\text { medium }\end{array}$ & 0.0008 & 7.14 & $2.26-22.57$ & 0.0131 & 4.97 & $1.40-17.66$ \\
\hline $\begin{array}{l}\text { MEG3 } \\
\text { expression }\end{array}$ & high vs low & 0.0071 & 4.67 & $3.82-12.75$ & 0.0270 & 4.21 & $1.18-15.04$ \\
\hline $\begin{array}{l}\text { MEG3 } \\
\text { expression }\end{array}$ & $\begin{array}{l}\text { high vs } \\
\text { medium }\end{array}$ & 0.0001 & 14.09 & $3.78-52.51$ & $<0.0001$ & 121.09 & $17.64-831.43$ \\
\hline $\begin{array}{l}\text { Sox2ot } \\
\text { expression }\end{array}$ & high vs low & 0.0008 & 9.49 & $2.54-35.39$ & 0.0001 & 24.44 & $5.11-116.97$ \\
\hline $\begin{array}{l}\text { Sox2ot } \\
\text { expression }\end{array}$ & $\begin{array}{l}\text { high vs } \\
\text { medium }\end{array}$ & 0.1035 & 2.41 & $0.84-6.92$ & 0.0056 & 6.49 & $1.73-24.40$ \\
\hline $\begin{array}{l}\text { Zeb2NAT } \\
\text { expression }\end{array}$ & high vs low & 0.0209 & 0.34 & $0.03-0.71$ & 0.0025 & 0.32 & $0.17-0.68$ \\
\hline $\begin{array}{l}\text { Zeb2NAT } \\
\text { expression }\end{array}$ & $\begin{array}{l}\text { high vs } \\
\text { medium }\end{array}$ & 0.0168 & 0.31 & $0.13-0.81$ & 0.0441 & 0.30 & $0.24-0.74$ \\
\hline $\begin{array}{l}\text { IGF2AS } \\
\text { expression }\end{array}$ & high vs low & & & & 0.0480 & 3.89 & $1.99-16.31$ \\
\hline $\begin{array}{l}\text { IGF2AS } \\
\text { expression }\end{array}$ & $\begin{array}{l}\text { high vs } \\
\text { medium }\end{array}$ & & & & 0.0118 & 5.34 & $1.45-19.69$ \\
\hline
\end{tabular}

HR: hazard ratio; CI: confidence interval.

therapy ineffectiveness. However, further studies in a larger cohort are needed to confirm these findings. The function of the above lncRNA in patients who are nonresponding to vemurafenib needs further evaluation.

\section{CONCLUSIONS}

Evaluation of plasma lncRNA expression levels for advanced melanoma diagnosis and prognosis evaluation is a safe and valuable method; however, it needs further validation in larger cohorts and randomized trials. We show that lncRNA IGF2AS, MEG3, and Zeb2NAT are independent prognostic factors in $B R A F$-mutated advanced melanoma patients treated with vemurafenib. Further validation of these biomarkers in larger cohorts of patients receiving a BRAF inhibitor combined with a MEK inhibitor is needed. The next step could include the evaluation of these circulating lncRNAs as predictive factors in a randomized study including melanoma patients receiving $\mathrm{BRAF}+\mathrm{MEK}$ inhibitors and immunotherapy.

\section{MATERIALS AND METHODS}

\section{Patients}

This retrospective study included BRAF mutant metastatic melanoma patients treated at one Polish oncology center. All patients received a BRAF inhibitor (vemurafenib) in a dose of $960 \mathrm{mg}$ twice daily. Blood samples were drawn from 58 melanoma patients and 15 healthy donors without histories of cancer or chronic diseases.

All donors were informed about the aim of the study, use of personal data, and genetic data protection. They agreed to use their material and they filled the consent form. The study methods conformed to the standards set by the Declaration of Helsinki and did not violate the rights of other persons or institutions. The bioethical committee approved the experimental study (agreement No. 13/2008).

Whole blood was collected into tubes containing ethylenediaminetetraacetic acid (EDTA) (SARSTED Monovette EDTA K) and immediately centrifuged (10 min at $1900 \times \mathrm{g}$, room temperature [RT]). The upper plasma phase was transferred to a new tube without disturbing the intermediate buffy coat layer. Next, the plasma samples were centrifuged (10 min at $16,000 \mathrm{xg}, \mathrm{RT})$ to remove cellular nucleic acids attached to cell debris, transferred to new tubes, and stored at $-80^{\circ} \mathrm{C}$ until use.

Overall survival (OS) was calculated from the date of vemurafenib treatment initiation to the date of death from any cause. Patients who were still alive were censored at the last follow-up. Progression-free survival (PFS) was calculated from the date of initiation of vermurafenib therapy until progression as documented by imaging according to response evaluation criteria in solid tumors (RECIST), clinical examination, or death. Those 
Table 6: Correlation between plasma IncRNA concentrations and clinical characteristics of $B R A F$-mutant advanced melanoma patients treated with vemurafenib (median [interquartile range])

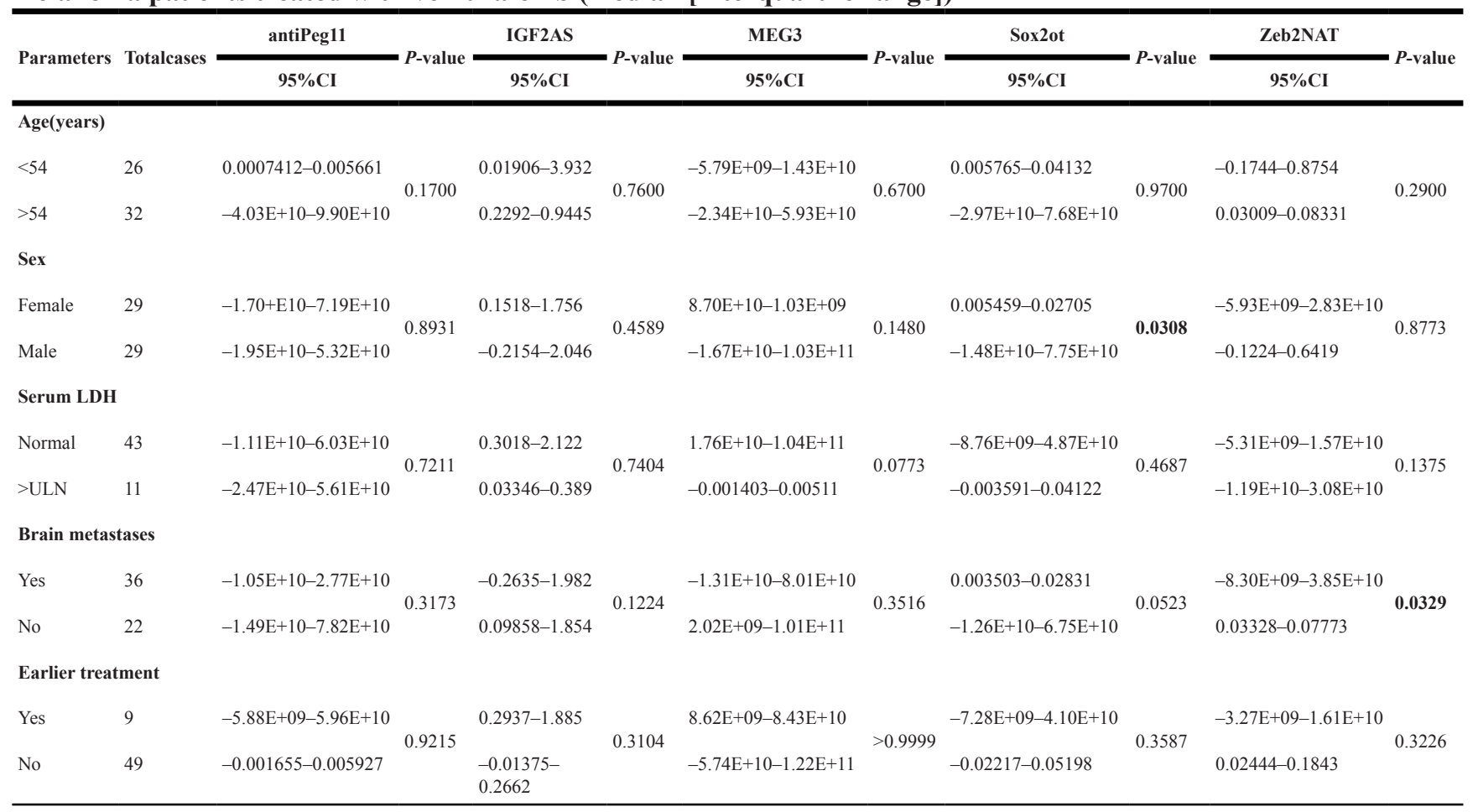

LDH - lactate dehydrogenase; ULN - upper laboratory norm; CI - confidence interval.

who were alive and without progression were censored at the last follow-up.

\section{RNA isolation}

Total RNA was isolated from plasma samples using miRNeasy Serum/Plasma Kit (Qiagen) according to the isolation protocol for total RNA. The quality and quantity of RNA samples were checked with a NanoDrop spectrophotometer (Thermo Scientific), and samples were stored at $-80^{\circ} \mathrm{C}$ until use.

\section{cDNA synthesis and $q R T-P C R$ reaction}

In this study, the 90 lncRNAs, potentially connected with cancer and well-annotated and registered in the lncRNA database (www.lncrnadb.org), were analyzed using the commercially available LncProfiler qPCR Array Kit (SBI).

Reverse transcription was performed according to the manufacturer's protocol and was based on three steps: i) poly-A tailing; ii) annealing anchor dT adaptor; and iii) cDNA synthesis.

cDNA was used for the qRT-PCR reaction using LightCycler 480 SYBR Green I Master buffer (Roche) and IncRNA primers from Primer Plate (component of the LncProfiler qPCR Array Kit) according to the manufacturer's protocol by the LightCycler 96 (Roche). All qRT-PCR data were analyzed by calculating the $\Delta \mathrm{C}_{\mathrm{t}}$, normalized against mean expression of anti-nitric oxide synthase
(NOS)2A+human accelerated region (HAR)1B+taurine upregulated gene (TUG)1, which were the most stable transcripts in all of the examined samples (healthy and cancer) with the lowest $\mathrm{C}_{t} \mathrm{~s}$ variation compared to the reference genes from the LncProfiler qPCR Array Kit (SBI). The fold-change of IncRNA expression was determined by equation $2^{-\Delta \mathrm{Ct}}$ and compared to the appropriate group.

\section{Statistical analysis}

Statistical analysis was performed with MedCalc version 10.3.2. (MedCalc Software, Mariakerke, Belgium) and Statistica 12 (StatSoft Inc., Poland). All data are presented as means \pm standard error (SEM). The lncRNAs expression profiles were compared between melanoma patients and controls.

Furthermore, the melanoma patients were grouped into similar clinical categories. The comparison of the IncRNAs expression profiles between analyzed groups was done by Student's $t$-test or the Mann-Whitney test if data did not follow a normal distribution. Normality was analyzed with the Shapiro-Wilks test. Receiver operating characteristics (ROC) curves were calculated. An optimal cut-off point was calculated according to the highest accuracy (minimal false negative and false positive rates). The area under the ROC curve (AUC) was used to assess the prognostic properties of each lncRNA. Kaplan-Meier survival curves for the analyzed groups were plotted, and the log-rank test was used to compare the survival 
probability curves. For further analyses, the samples ordered based on their lncRNA levels were stratified into three groups of lncRNA expression: (1) low; (2) medium; and (3) high based on the three tertiles as shown in Table 3. A Cox proportional hazards regression model was used to determine which lncRNAs were significantly associated with both OS and PFS. The results were expressed as the hazard ratios (HRs) and 95\% confidence intervals (CIs). All of the tests were performed as two-tailed tests and were considered significant at $p<0.05$.

\section{Ethics approval}

Study is based on human blood samples. All donors were informed about the aim of the study, personal data and genetic data protection, and they agreed to use their material. The experiments were undertaken with the understanding and written consent of each subject. The study methodologies conformed to the standards set by the Declaration of Helsinki. Study does not violate the rights of other persons or institutions. Bioethical committee approved this study - agreement No. 13/2008.

\section{CONFLICTS OF INTEREST} interests.

The authors declare that they have no competing

\section{FUNDING}

This work was supported by the National Science Centre, Poland, allocated on the basis of decision no.: 2016/21/B/NZ7/01773. Samples collection was supported by grant of Polish Oncological Society (PTO) for K. Kozak signed on December 20, 2014.

\section{REFERENCES}

1. McArthur GA, Chapman PB, Robert C, Larkin J, Haanen JB, Dummer R, Ribas A, Hogg D, Hamid O, Ascierto PA, Garbe C, Testori A, Maio M, et al. Safety and efficacy of vemurafenib in BRAF(V600E) and BRAF(V600K) mutationpositive melanoma (BRIM-3): extended follow-up of a phase 3, randomised, open-label study. Lancet Oncol. 2014; 15:323-32. https://doi.org/10.1016/S1470-2045(14)70012-9. [PubMed]

2. Long GV, Stroyakovskiy D, Gogas H, Levchenko E, de Braud F, Larkin J, Garbe C, Jouary T, Hauschild A, Grob JJ, Chiarion-Sileni V, Lebbe C, Mandalà M, et al. Dabrafenib and trametinib versus dabrafenib and placebo for Val600 BRAF-mutant melanoma: a multicentre, double-blind, phase 3 randomised controlled trial. Lancet. 2015; 386:444-51. https://doi.org/10.1016/S0140-6736(15)60898-4. [PubMed]

3. Robert C, Karaszewska B, Schachter J, Rutkowski P, Mackiewicz A, Stroiakovski D, Lichinitser M, Dummer R, Grange F, Mortier L, Chiarion-Sileni V, Drucis K, Krajsova I, et al. Improved overall survival in melanoma with combined dabrafenib and trametinib. N Engl J Med. 2015; 372:30-39. https://doi.org/10.1056/NEJMoa1412690. [PubMed]

4. Robert C, Karaszewska B, Schachter J, Rutkowski P, Mackiewicz A, Stroyakovskiy D, Dummer R, Grange F, Mortier L, Chiarion-Sileni V, Drucis K, Krajsová I, Hauschild A, et al. Three-year estimate of overall survival in COMBI-v, a randomized phase 3 study evaluating first-line dabrafenib (D) + trametinib (T) in patients (pts) with unresectable or metastatic BRAF V600E/K-mutant cutaneous melanoma. Ann Oncol. 2016; 27:S1-36. https:// doi.org/10.1093/annonc/mdw435.37.

5. Grob JJ, Amonkar MM, Karaszewska B, Schachter J, Dummer R, Mackiewicz A, Stroyakovskiy D, Drucis K, Grange F, Chiarion-Sileni V, Rutkowski P, Lichinitser M, Levchenko E, et al. Comparison of dabrafenib and trametinib combination therapy with vemurafenib monotherapy on health-related quality of life in patients with unresectable or metastatic cutaneous BRAF Val600-mutation-positive melanoma (COMBI-v): results of a phase 3, open-label, randomised trial. Lancet Oncol. 2015; 16:1389-98. https:// doi.org/10.1016/S1470-2045(15)00087-X. [PubMed]

6. Larkin J, Ascierto PA, Dréno B, Atkinson V, Liszkay G, Maio M, Mandalà M, Demidov L, Stroyakovskiy D, Thomas L, de la Cruz-Merino L, Dutriaux C, Garbe C, et al. Combined vemurafenib and cobimetinib in BRAF-mutated melanoma. N Engl J Med. 2014; 371:1867-76. https://doi. org/10.1056/NEJMoa1408868. [PubMed]

7. McArthur GA, Dréno B, Atkinson V. Efficacy of Long-Term Cobimetinib + Vemurafenib in Advanced BRAFV600Mutated Melanoma: 3-Year Follow-up of coBRIM (Phase 3 ) and 4-year Follow-Up of BRIM7 (Phase 1b). Society for Melanoma Research 2016 Congress. November 6-9, 2016; Boston, MA, USA.

8. Amaral T, Sinnberg T, Meier F, Krepler C, Levesque M, Niessner H, Garbe C. MAPK pathway in melanoma part II-secondary and adaptive resistance mechanisms to BRAF inhibition. Eur J Cancer. 2017; 73:93-101. https://doi. org/10.1016/j.ejca.2016.12.012. [PubMed]

9. Long GV, Grob JJ, Nathan P, Ribas A, Robert C, Schadendorf D, Lane SR, Mak C, Legenne P, Flaherty KT, Davies MA. Factors predictive of response, disease progression, and overall survival after dabrafenib and trametinib combination treatment: a pooled analysis of individual patient data from randomised trials. Lancet Oncol. 2016; 17:1743-54. https://doi.org/10.1016/S14702045(16)30578-2. [PubMed]

10. Maleki Vareki S, Garrigós C, Duran I. Biomarkers of response to PD-1/PD-L1 inhibition. Crit Rev Oncol Hematol. 2017; 116:116-24. https://doi.org/10.1016/j. critrevonc.2017.06.001. [PubMed]

11. Rozeman EA, Dekker TJ, Haanen JB, Blank CU. Advanced Melanoma: Current Treatment Options, Biomarkers, and Future Perspectives. Am J Clin Dermatol. 2018; 19:303-17. https://doi.org/10.1007/s40257-017-0325-6. [PubMed] 
12. Lim SY, Lee JH, Diefenbach RJ, Kefford RF, Rizos H. Liquid biomarkers in melanoma: detection and discovery. Mol Cancer. 2018; 17:8. https://doi.org/10.1186/s12943-018-0757-5. [PubMed]

13. Huang SK, Hoon DS. Liquid biopsy utility for the surveillance of cutaneous malignant melanoma patients. Mol Oncol. 2016; 10:450-63. https://doi.org/10.1016/j. molonc.2015.12.008. [PubMed]

14. Gaiser MR, von Bubnoff N, Gebhardt C, Utikal JS. Liquid biopsy to monitor melanoma patients. J Dtsch Dermatol Ges. 2018; 16:405-14. https://doi.org/10.1111/ddg.13461. [PubMed]

15. Pös O, Biró O, Szemes T, Nagy B. Circulating cell-free nucleic acids: characteristics and applications. Eur J Hum Genet. 2018; 26:937-45. https://doi.org/10.1038/s41431018-0132-4. [PubMed]

16. Kolenda T, Guglas K, Ryś M, Bogaczyńska M, Teresiak A, Bliźniak R, Łasińska I, Mackiewicz J, Lamperska KM. Biological role of long non-coding RNA in head and neck cancers. Rep Pract Oncol Radiother. 2017; 22:378-88. https://doi.org/10.1016/j.rpor.2017.07.001. [PubMed]

17. Guglas K, Bogaczyńska M, Kolenda T, Ryś M, Teresiak A, Bliźniak R, Łasińska I, Mackiewicz J, Lamperska K. lncRNA in HNSCC: challenges and potential. Contemp Oncol (Pozn). 2017; 21:259-66. https://doi.org/10.5114/ wo.2017.72382. [PubMed]

18. MacKie RM, Hauschild A, Eggermont AM. Epidemiology of invasive cutaneous melanoma. Ann Oncol. 2009; 20:vi17. https://doi.org/10.1093/annonc/mdp252. [PubMed]

19. Jiang W, Jia P, Hutchinson KE, Johnson DB, Sosman JA, Zhao Z. Clinically relevant genes and regulatory pathways associated with NRASQ61 mutations in melanoma through an integrative genomics approach. Oncotarget. 2015; 6:2496-508. https://doi.org/10.18632/oncotarget.2954. [PubMed]

20. Mackiewicz-Wysocka M, Krokowicz L, Kocur J, Mackiewicz J. Resistance to vemurafenib can be reversible after treatment interruption: a case report of a metastatic melanoma patient. Medicine (Baltimore). 2014; 93:e157. https://doi.org/10.1097/MD.0000000000000157. [PubMed]

21. Mackiewicz J, Mackiewicz A. BRAF and MEK inhibitors in the era of immunotherapy in melanoma patients. Contemp Oncol (Pozn). 2018; 22:68-72. https://doi.org/10.5114/ wo.2018.73890. [PubMed]

22. Mackiewicz J, Mackiewicz A. Programmed cell death 1 checkpoint inhibitors in the treatment of patients with advanced melanoma. Contemp Oncol (Pozn). 2017; 21:1-5. https://doi.org/10.5114/wo.2017.66651. [PubMed]

23. Rutkowski P, Kozak K, Mackiewicz J, Krzemieniecki K, Nawrocki S, Wasilewska-Teśluk E, Kwinta Ł, Wysocki P, Koseła-Paterczyk H, Świtaj T. The outcomes of Polish patients with advanced BRAF-positive melanoma treated with vemurafenib in a safety clinical trial. Contemp
Oncol (Pozn). 2015; 19:280-83. https://doi.org/10.5114/ wo.2015.54082. [PubMed]

24. Zhuang J, Lu Q, Shen B, Huang X, Shen L, Zheng X, Huang R, Yan J, Guo H. TGF $\beta 1$ secreted by cancerassociated fibroblasts induces epithelial-mesenchymal transition of bladder cancer cells through lncRNAZEB2NAT. Sci Rep. 2015; 5:11924. https://doi.org/10.1038/ srep11924. [PubMed]

25. Xue G, Kohler R, Tang F, Hynx D, Wang Y, Orso F, Prêtre V, Ritschard R, Hirschmann P, Cron P, Roloff T, Dummer R, Mandalà $\mathrm{M}$, et al. mTORC1/autophagy-regulated MerTK in mutant BRAFV600 melanoma with acquired resistance to BRAF inhibition. Oncotarget. 2017; 8:69204-18. https:// doi.org/10.18632/oncotarget.18213. [PubMed]

26. Livingstone C. IGF2 and cancer. Endocr Relat Cancer. 2013; 20:R321-39. https://doi.org/10.1530/ERC-13-0231. [PubMed]

27. Song C, Song C, Chen K, Zhang X. Inhibition of long non-coding RNA IGF2AS protects apoptosis and neuronal loss in anesthetic-damaged mouse neural stem cell derived neurons. Biomed Pharmacother. 2017; 85:218-24. https:// doi.org/10.1016/j.biopha.2016.10.094. [PubMed]

28. Zhang X, Chen K, Song C, Song C. Inhibition of long non-coding RNA IGF2AS has profound effect on inducing neuronal growth and protecting local-anesthetic induced neurotoxicity in dorsal root ganglion neurons. Biomed Pharmacother. 2016; 82:298-303. https://doi.org/10.1016/j. biopha.2016.04.042. [PubMed]

29. Zhang X, Zhang X, Hu R, Hao L. Retraction: Prognostic implication and functional role of long noncoding RNA IGF2AS in human non-small cell lung cancer. J Cell Biochem. 2019; 120:12067. https://doi.org/10.1002/ jeb.26113. [PubMed]

30. Long J, Pi X. IncRNA-MEG3 Suppresses the Proliferation and Invasion of Melanoma by Regulating CYLD Expression Mediated by Sponging miR-499-5p. BioMed Res Int. 2018; 2018:2086564. https://doi.org/10.1155/2018/2086564. [PubMed]

31. Han L, Zhang W, Zhang B, Zhan L. Long non-coding RNA SOX2OT promotes cell proliferation and motility in human ovarian cancer. Exp Ther Med. 2018; 15:2182-88. https:// doi.org/10.3892/etm.2017.5618. [PubMed]

32. Su R, Cao S, Ma J, Liu Y, Liu X, Zheng J, Chen J, Liu L, Cai H, Li Z, Zhao L, He Q, Xue Y. Knockdown of SOX2OT inhibits the malig- nant biological behaviors of glioblastoma stem cells via up-regulating the expression of miR-194-5p and miR-122. Mol Cancer. 2017; 16:171. https://doi. org/10.1186/s12943-017-0737-1. [PubMed]

33. Tang X, Gao Y, Yu L, Lu Y, Zhou G, Cheng L, Sun K, Zhu B, Xu M, Liu J. Correlations between lncRNA-SOX2OT polymorphism and susceptibility to breast cancer in a Chinese population. Biomarkers Med. 2017; 11:277-84. https://doi.org/10.2217/bmm-2016-0238. [PubMed]

34. Liu S, Xu B, Yan D. Enhanced expression of long noncoding RNA Sox2ot promoted cell proliferation and 
motility in colorectal cancer. Minerva Med. 2016; 107:27986. [PubMed]

35. Shafiee M, Aleyasin SA, Vasei M, Semnani SS, Mowla SJ. Down- regulatory effects of miR-211 on long non-coding RNA SOX2OT and SOX2 genes in esophageal squamous cell carcinoma. Cell J. 2016; 17:593-600. https://doi. org/10.1002/stem.1542. [PubMed]

36. Shi XM, Teng F. Up-regulation of long non-coding RNA Sox2ot promotes hepatocellular carcinoma cell metastasis and correlates with poor prognosis. Int J Clin Exp Pathol. 2015; 8:4008-14. [PubMed]

37. Farhangian P, Jahandoost S, Mowla SJ, Khalili M. Differential expression of long non-coding RNA SOX2OT in gastric adenocarcinoma. Cancer Biomark. 2018; 23:22125. https://doi.org/10.3233/CBM-181325. [PubMed]

38. Xie Y, Zhang Y, Du L, Jiang X, Yan S, Duan W, Li J, Zhan Y, Wang L, Zhang S, Li S, Wang L, Xu S, Wang C. Circulating long noncoding RNA act as potential novel biomarkers for diagnosis and prognosis of non-small cell lung cancer. Mol Oncol. 2018; 12:648-58. https://doi. org/10.1002/1878-0261.12188. [PubMed]

39. Nie F, Yu X, Huang M, Wang Y, Xie M, Ma H, Wang Z, De W, Sun M. Long noncoding RNA ZFAS1 promotes gastric cancer cells proliferation by epigenetically repressing KLF2 and NKD2 expression. Oncotarget. 2017; 8:38227-38. https://doi.org/10.18632/oncotarget.9611. [PubMed]

40. Fang C, Zan J, Yue B, Liu C, He C, Yan D. Long Noncoding RNA ZFAS1 promotes the progression of colonic cancer by modulating ZEB1 expression. J Gastroenterol Hepatol. 2016; 32:1204-11. https://doi.org/10.1111/jgh.13646. [PubMed]

41. Gao K, Ji Z, She K, Yang Q, Shao L. Long non-coding RNA ZFAS1 is an unfavourable prognostic factor and promotes glioma cell progression by activation of the Notch signaling pathway. Biomed Pharmacother. 2017; 87:555-60. https:// doi.org/10.1016/j.biopha.2017.01.014. [PubMed]

42. Xia B, Hou Y, Chen H, Yang S, Liu T, Lin M, Lou G. Long non-coding RNA ZFAS1 interacts with miR-150-5p to regulate $\mathrm{Sp} 1$ expression and ovarian cancer cell malignancy. Oncotarget. 2017; 8:19534-46. https://doi.org/10.18632/ oncotarget.14663. [PubMed]

43. Tian FM, Meng FQ, Wang XB. Overexpression of longnoncoding RNA ZFAS1 decreases survival in human NSCLC patients. Eur Rev Med Pharmacol Sci. 2016; 20:5126-31. [PubMed]
44. Li T, Xie J, Shen C, Cheng D, Shi Y, Wu Z, Deng X, Chen H, Shen B, Peng C, Li H, Zhan Q, Zhu Z. Amplification of long noncoding RNA ZFAS1 promotes metastasis in hepatocellular carcinoma. Cancer Res. 2015; 75:3181-91. https://doi.org/10.1158/0008-5472.CAN-14-3721. [PubMed]

45. Li N, Sun ZH, Fang M, Xin JY, Wan CY. Long non-coding RNA ZFAS1 sponges miR-486 to promote osteosarcoma cells progression and metastasis in vitro and vivo. Oncotarget. 2017; 8:104160-70. https://doi.org/10.18632/ oncotarget.22032. [PubMed]

46. Lv QL, Chen SH, Zhang X, Sun B, Hu L, Qu Q, Huang YT, Wang GH, Liu YL, Zhang YY, Zhou HH. Upregulation of long noncoding RNA zinc finger antisense 1 enhances epithelialmesenchymal transition in vitro and predicts poor prognosis in glioma. Tumour Biol. 2017; 39:1010428317695022. https://doi.org/10.1177/1010428317695022. [PubMed]

47. Xie S, Ge Q, Wang X, Sun X, Kang Y. Long non-coding RNA ZFAS1 sponges miR-484 to promote cell proliferation and invasion in colorectal cancer. Cell Cycle. 2018; 17:154-61. https://doi.org/10.1080/15384101.2017.1407895. [PubMed]

48. Wang W, Xing C. Upregulation of long noncoding RNA ZFAS1 predicts poor prognosis and prompts invasion and metastasis in colorectal cancer. Pathol Res Pract. 2016; 212:690-95. https://doi.org/10.1016/j.prp.2016.05.003. [PubMed]

49. Fan S, Fan C, Liu N, Huang K, Fang X, Wang K. Downregulation of the long non-coding RNA ZFAS1 is associated with cell proliferation, migration and invasion in breast cancer. Mol Med Rep. 2018; 17:6405-12. https://doi. org/10.3892/mmr.2018.8707. [PubMed]

50. White RJ. RNA polymerase III transcription and cancer. Oncogene. 2004; 23:3208-16. https://doi.org/10.1038/ sj.onc.1207547. [PubMed]

51. Abdelmohsen K, Panda AC, Kang MJ, Guo R, Kim J, Grammatikakis I, Yoon JH, Dudekula DB, Noh JH, Yang X, Martindale JL, Gorospe M. 7SL RNA represses p53 translation by competing with HuR. Nucleic Acids Res. 2014; 42:10099-111. https://doi.org/10.1093/nar/gku686. [PubMed] 